\title{
Basaal wetenschappelijk bewijs voor de link tussen erectiele disfunctie en cardiometabole disfunctie
}

\author{
Herman H. J. Leliefeld ${ }^{1}$
}

Published online: 25 November 2016

(C) The Author(s) 2016. This article is available at SpringerLink with Open Access.

\begin{abstract}
Samenvatting In 2012 heeft de Sexual Medicine Society of North America (SMSNA) een commissie ingesteld, die als opdracht had het wetenschappelijk bewijs te onderzoeken voor een pathomechanistische link tussen erectiele disfunctie (ED) en cardiovasculaire metabole ziekten (CVMZ). In deze review doet de commissie verslag van haar bevindingen, na een literatuuronderzoek van vijf betrokken onderdelen van het erectiemechanisme. De commissie constateert dat er verscheidene fundamenteel wetenschappelijke bewijzen zijn, met gemeenschappelijke pathomechanismen, voor de link tussen ED en CVMZ, zoals een disbalans in de stikstofoxideproductie door de endotheelcel met oxidatieve stress, een veranderde moleculaire regulatie van de gladde spieren, autonome neuropathie en een verminderde afgifte van stikstofoxide door de neuronen, een daling van de testosteronspiegel met gevolgen voor de werking ervan, en de toegenomen glycatie met vorming van eindproducten en hyperlipidemie bij metabole ziekten. De commissie benadrukt grote leemten in kennis en doet voorstellen voor verder wetenschappelijk onderzoek naar deze relatie.
\end{abstract}

Trefwoorden endotheel $\cdot$ gladde spieren $\cdot$ autonome regulatie $\cdot$ hormonen $\cdot$ metabolica

Dit artikel is een verkorte Nederlandstalige weergave van een uitgebreide review met dezelfde titel: Musicki B, Bella A, Bivalacqua TJ, et al. J Sex Med. 2015;12:2233-55 [1].

\footnotetext{
$\square$ dr. Herman H. J. Leliefeld

hleliefe@kpnmail.nl

1 Andros Mannenkliniek, Baarn, Nederland
}

\section{Basic scientific evidence for the link between erectile dysfunction and cardiometabolic dysfunction}

\begin{abstract}
In 2012 the Basic Science Committee of the Sexual Medicine Society of North America (SMSNA) was commissioned to conduct a comprehensive literature review to evaluate the evidence basis for a mechanistic link between Erectile Dysfunction (ED) and Cardiovascular Metabolic Diseases (CVMD). The Committee concluded that basic science evidence supports this link on several grounds with common pathomechanistics: endothelial dysfunction with nitric oxide and oxidative stress imbalance, altered molecular regulation of smooth muscle contractility, impaired testosterone release and actions, and advanced glycation end product formation and hyperlipidemia in metabolic diseases. The Committee also highlighted gaps in knowledge and provided recommendations for further scientific research for defining this risk relationship.
\end{abstract}

Keywords endothelium $\cdot$ smooth muscle $\cdot$ autonomic regulation $\cdot$ hormones $\cdot$ metabolics

\section{Introductie}

De term erectiele disfunctie (ED) wordt tegenwoordig gebezigd in zowel de medische wetenschappelijke literatuur als de lekenpers en wordt doorgaans wel begrepen als een term die wijst op een stoornis van de seksualiteit. De klinische implicaties van de term ED zijn echter zeer talrijk en zijn vermoedelijk minder goed begrepen. ED wordt gedefinieerd als 'het voortdurend of terugkerend onvermogen om een adequate erectie te verkrijgen en te handhaven, voldoende voor voltooiing van de geslachtsgemeenschap' [2]. 
Daarmee is ED goed afgegrensd van vele andere seksuele stoornissen. De term ED beschrijft een symptoom, zonder daarbij aan te geven bij welke ziekte het symptoom hoort.

Toch heeft ED een duidelijk verband met bekende ziekten, zoals DM2, hypertensie en perifere vaatafwijkingen [3]. Cardiovasculaire en metabole ziekten (CVMZ) hebben een zeer sterke link met ED, en talrijke studies hebben deze associatie aangetoond [4, 5]. Zo toonde Montorsi in 2003 aan dat ED vooraf kan gaan aan cardiovasculaire ziekten (CVZ): bij 300 patiënten met acute pijn op de borst met vervolgens angiografisch bewezen atherosclerose van de coronaire arteriën, was reeds in $49 \%$ van de gevallen vooraf sprake van ED en in $67 \%$ van de gevallen trad ED op voorafgaand aan klachten van CVZ [4]. Als verklaring hiervoor werden de peniele corpora cavernosa beschouwd als onderdeel van het vaatstelsel, en dus zou een stoornis van de fysiologische functie bij de één ook optreden bij de ander.

De placebo-arm van de Prostate Prevention Cancer Trial toonde eveneens aan dat ED een signaal is voor toekomstige cardiovasculaire afwijkingen, vergelijkbaar met het risico van roken en een familiare belasting van een myocardinfarct: zo hadden mannen met ED een $45 \%$ hogere kans op een cardiovasculaire afwijking dan mannen zonder ED gedurende een follow-up van vijf jaar [6].

Ook de ernst van ED correleerde met de mate van atherosclerose van de coronaire vaten [7].

Drie recente meta-analyses van longitudinale studies geven interessante relatieve risicoratio's (RR) voor CVZ en mortaliteit voor mannen met ED; de grootste wordt hier geciteerd. In een groot cohortonderzoek onder 95.038 mannen zonder CVZ vooraf, bedroeg het RR voor mannen met ernstige $\mathrm{ED}$, vergeleken met mannen zonder $\mathrm{ED}, 1,60$ voor ischemische hartziekte, 8,00 voor hartfalen, 1,92 voor perifeer vaatlijden en 1,93 voor algehele mortaliteit [8].

Dit klinisch-epidemiologisch bewijs van een link tussen ED en CVMZ is voor verscheidene organisaties aanleiding geweest om de aanwezigheid van ED te beschouwen als een barometer of biomarker voor de gezondheidsstatus en als een voorbode voor CVMZ. Zo heeft de Princeton III Consensus Conferentie, een multidisciplinair forum, in 2012 verklaard dat alle mannen met ED potentieel risicodragers zijn voor CVZ en het forum adviseert dan ook om bij mannen met ED de vasculaire risicofactoren op te sporen en agressief te behandelen [9].

Terwijl er een toenemende bewustwording ontstaat in de klinische praktijk om ED en CVMZ tezamen te onderzoeken/behandelen, blijft het van groot belang om de link tussen ED en CVMZ ook pathomechanistisch te verklaren.

Een wijdverbreide verklaring voor de link is het concept dat ED veroorzaakt wordt door endotheeldisfunctie (ED), met als dogma 'ED = ED', wat suggereert dat dit pathomechanisme van endotheeldisfunctie op het niveau van de penisvascularisatie dezelfde uitwerking heeft als in de overige lichaamsvaten. Echter, het is zeer wel mogelijk dat vele andere pathomechanismen verantwoordelijk zijn voor de link tussen ED en CVMZ, náást de endotheeldisfunctie. Afgezien van de vasculaire component, zijn er vermoedelijk ook andere functionele systemen bij betrokken, zoals het zenuwstelsel, de hormoonregulatie en de metabole status, met hun moleculaire mechanismen. Het moge duidelijk zijn dat het basaal wetenschappelijk bewijs voor de link tussen ED en CVMZ nog niet compleet is opgehelderd.

In 2012 werd daarom een commissie ingesteld door de Sexual Medicine Society of North America (SMSNA) met de opdracht om het huidige wetenschappelijk bewijs te onderzoeken voor een pathomechanistische link tussen ED en CVMZ. Daarbij dient deze commissie aan de hand van de wetenschappelijke literatuur te bepalen:

- of er een bepaalde link bestaat en wat de wetenschappelijke basis ervan is;

- welke toekomstige wetenschappelijke studies nodig zijn om het relatieve risico op een dergelijke samenhang nader te bepalen;

- met daaruit voortvloeiend nieuwe therapeutische strategieën.

In deze review doet deze commissie verslag van haar bevindingen in vijf secties met aandacht voor de functionele systemen die van belang zijn voor de fysiologie van de erectie, zoals het endotheel, de gladde spieren, de autonome regulatie, de hormonale huishouding en het metabolisme.

\section{Het endotheel}

De penis is een zeer sterk gevasculariseerd orgaan en de erectie ontstaat voornamelijk door een neurovasculair mechanisme waarvoor een intact endotheel vereist is, in samenhang met gladde spieren en een intact zenuwstelsel. Het endotheel, de binnenbekleding van de wand van de arterie, produceert verscheidene vasodilatoire factoren, waarvan het stikstofoxide (NO) het meest bekend is (fig. 1; [10]). Iedere verstoring van de endotheelcelfunctie kan de peniele bloedflow aantasten en daarmee de erectie. Endotheeldisfunctie leidt tot atherosclerose en in bredere zin ook tot een veranderde anticoagulatie, pro-inflammatoire activiteiten en het onvermogen van het vaatbed zich om te vormen. Deze endotheeldisfunctie komt voor bij belangrijke cardiometabole risicofactoren, zoals DM, hypertensie, hypercholesterolemie, obesitas, een sedentaire levensstijl, roken en ouder worden. Endotheeldisfunctie kan in ieder vaatbed optreden en wordt beschouwd als een gemeenschappelijke noemer als zowel ED als perifeer vaatlijden optreedt, waarmee het een plausibele link vormt tussen ED en CVMZ. De verminderde signaalwerking van NO en de oxidatieve stress zijn 
Figuur 1 Regulatie van de relaxatie van de gladde spieren van het peniele corpus cavernosum in samenhang met de endotheelcellen en de zenuwuiteinden. $A T P$ adenosine triphosphate; cAMP cyclic adenosine monophosphate; $c G M P$ cyclic guanosine monophosphate; $e N O S$ endothelial nitric oxide synthase; GTP guanosine-5-triphosphate; IP3 inositol triphosphate; $N O$ nitric oxide; $P D E$ phosphodiesterase. Bron: Hatzimouratidis et al. [10], naar Lue [49].

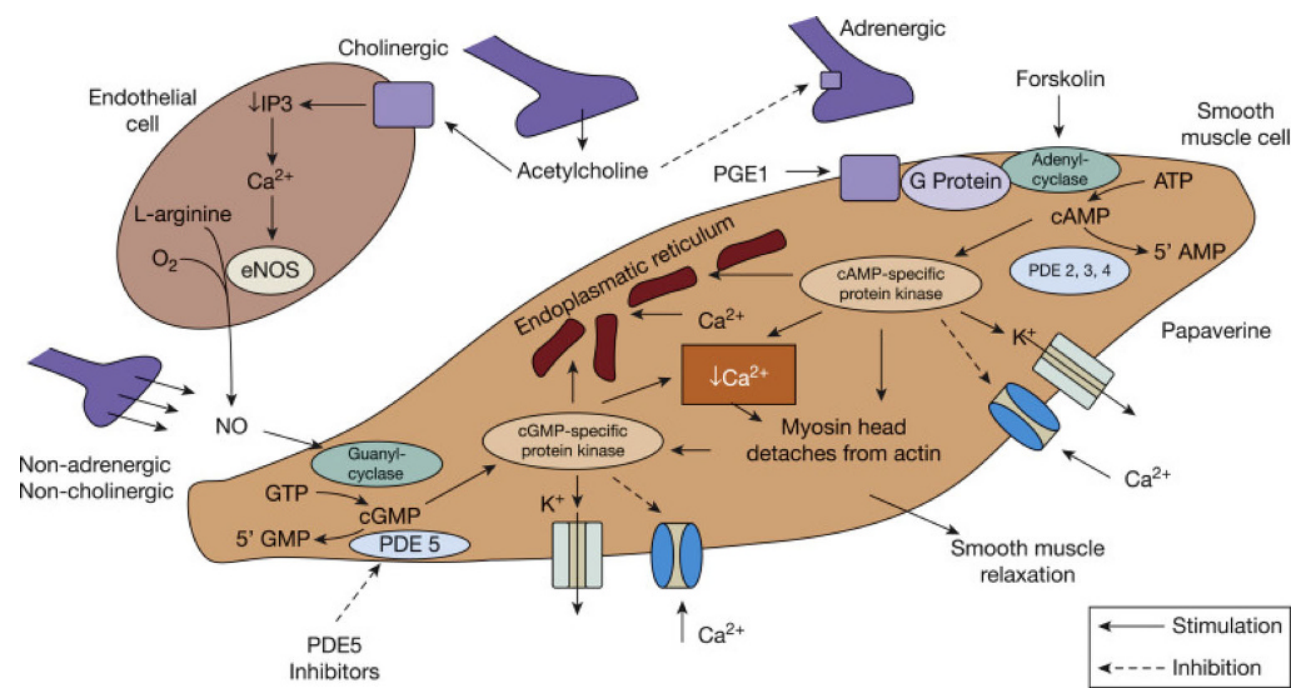

sleutelmechanismen die leiden tot stoornissen van het vaatsysteem in het algemeen en van het vaatbed van de penis in het bijzonder.

Er zijn vele aanwijzingen dat ED twee tot drie jaar eerder optreedt dan het klinisch manifest worden van CVZ $[4,11]$. In dierexperimenteel onderzoek kon worden aangetoond dat de ontwikkeling van endotheeldisfunctie tijdsafhankelijk is en het eerst optreedt in het vaatbed van de penis en later in de aorta of coronaire en mesenteriale arteriën [12].

Wat is nu precies de rol van de endotheelcellen in de link tussen ED en CVMZ? Een van de hypothesen die zijn geformuleerd om te verklaren waarom ED voorafgaat aan CVMZ is de 'hypothese van de diameter van de arterie'. Volgens deze hypothese zal het erectieweefsel eerder te maken krijgen met endotheeldisfunctie, atherosclerose en een verminderde doorbloeding wegens een kleine diameter, gedefinieerd als $<1-2 \mathrm{~mm}$, terwijl de coronaire vaten met een diameter van 3-4 $\mathrm{mm}$ een lichte vernauwing nog lange tijd kunnen compenseren zonder grote veranderingen in de bloedflow [13]. Deze diameterhypothese gaat uit van de aanname dat de gehele vaatboom bedekt is met hetzelfde endotheel en dat vaatafwijkingen ieder type vaatbed op dezelfde manier aantasten. Echter, er zijn aanwijzingen dat het endotheel van het penisvaatbed unieke eigenschappen heeft, die nodig zijn om die hoge drukken te bereiken in de sinusoïdale ruimte van het caverneuze weefsel die nodig zijn voor de erectie; aantasting van de verbindingen tussen de endotheelcellen onderling, specifiek voor de endotheelcellen van de penisarteriën, zou dan kunnen leiden tot veno-occlusieve disfunctie met ED tot gevolg [14]. Figuur 1 toont de relatie tussen de endotheelcel en de gladde spiercel van het corpus cavernosum met $\mathrm{NO}$ als belangrijke neurotransmitter voor de regulatie van de erectie.

\section{De gladde spieren}

De stimulus voor een erectie start in de hersenen en leidt via de autonome zenuwbanen naar de corpora cavernosa in de penis, tot een uitstoot van stikstofoxide (NO) aan zowel de zenuwuiteinden als de endotheelcellen; dit vormt de moleculaire basis voor het mechanisme van de erectie, met een aldus gereguleerde contractie en relaxatie van de gladde spieren van het corpus cavernosum (fig. 1; $[10,15])$. Iedere verandering in de hoeveelheid gladde spieren en deze moleculaire regulatie van de gladde spieren zal kunnen leiden tot ED. Uit dierexperimenteel onderzoek blijkt dat er grote verschillen bestaan tussen het corpus cavernosum en de aorta aangaande de moleculaire mechanismen die de contractiliteit van de gladde spieren reguleren [16]. Daarmee zouden de gladde spieren van het corpus cavernosum kwetsbaarder zijn voor pathologische processen dan de aorta, hetgeen de verklaring zou kunnen zijn voor het eerder optreden van $\mathrm{ED}$, voorafgaande aan klinische verschijnselen van gegeneraliseerd vaatlijden. Nader onderzoek zou kunnen leiden tot nieuwe en effectieve moleculen, die dan kunnen resulteren in nieuwe vormen van therapie voor ED.

De aanname dat atherosclerose een significante factor is in het ontstaan van ED [17] moet kritisch worden beschouwd. Weliswaar zal atherosclerose de bloedstroom naar de penis verminderen door verdikking van de tunica intima en media, maar deze arteriële insufficiëntie verklaart onvoldoende de meest voorkomende oorzaak van ED, te weten de corporale veno-occlusieve disfunctie waarbij de gladde spieren van de corpora cavernosa niet voldoende kunnen relaxeren om de uittredende venen dicht te drukken tegen de starre tunica albuginea [18]. Uit recent onderzoek komen aanwijzingen naar voren dat het corporale vasculaire en trabeculaire weefsel zich niet op dezelfde wijze gedraagt als het cardiovasculaire systeem. Zo werd bijvoorbeeld bij autopsie in de peniele vaten bij slechts $13 \%$ 
van de mannen atherosclerose gevonden, terwijl coronaire en perifere sclerose bij wel $80 \%$ van de onderzochte mannen werd vastgesteld [19]. De vraag is dan ook of niet juist de verdikking van de tunica intima en media van de arteria cavernosa bij ED-patiënten beschouwd moet worden als een belangrijk teken van arteriosclerose of arteriële stijfheid [20]. De hier beschreven uitkomsten maken duidelijk dat het breed geaccepteerde concept dat endotheeldisfunctie en atherosclerose verband houden met het ontstaan van ED, hernieuwde aandacht behoeft. Mogelijk leiden de arteriosclerose of de arteriële stijfheid door fibrose en het verlies van gladde spieren in de media (niet dus atherosclerose), zoals wordt gezien bij veroudering en DM2, tot corporale fibrose en veno-occlusieve disfunctie, en leiden juist deze tot ED [16]. De relaxatie van de gladde spieren is immers het doelwit van de PDE-5-remmers.

\section{De autonome regulatie}

Het bewijs voor ED als voorbode van CVZ is voornamelijk gebaseerd op een gemeenschappelijke pathofysiologie van endotheeldisfunctie - met gemeenschappelijke risicofactoren, zoals hypertensie, hypercholesterolemie, roken en DM2 - als ook op klinische studies die het verhoogde risico op CVZ aantonen bij patiënten met ED [21]. ED is doorgaans het gevolg van een combinatie van vasculaire en neuronale risicofactoren. Zonder atherosclerotische afwijkingen in het peniele vaatbed zou autonome disregulatie kunnen leiden tot ED. Dit roept dan de vraag op in hoeverre deze autonome disregulatie de verbindende schakel kan zijn tussen ED en CVZ/metabool syndroom (MetS).

De peniele erectie komt tot stand door een spinale reflex met stimuli van perifere zenuwen en vanuit het centraal zenuwstelsel [22]. De autonome zenuwvezels (sympathische en parasympathische) in de caverneuze zenuwplexus zijn verantwoordelijk voor de balans tussen contractie en relaxatie van de gladde spieren van de corpora cavernosa; hiermee wordt de instroom van bloed in de corpora cavernosa geregeld, met erectie en detumescentie tot gevolg. Er zijn geen processen bekend die specifiek de sympathische dan wel de parasympathische zenuwen onderbreken. Autonome neuropathie, zoals bij DM2 en na radicale prostatectomie, wordt in de VS beschouwd als de voornaamste oorzaak van ED [23].

Uit klinische studies blijkt dat mannen met DM een driemaal zo grote kans hebben op ED als niet-diabetische mannen [24]. DM kan ieder onderdeel van het autonome zenuwstelsel aandoen, dus zowel in het bereik van het genitale stelsel als in het cardiovasculaire systeem. Deze autonome neuropathie kan optreden binnen één jaar na de diagnose van DM en zelfs al daaraan voorafgaan [25]. Autonome disregulatie is ook vastgesteld bij hypertensie, hypercho- lesterolemie en het MetS. Deze disregulatie leidt tot een verhoogde sympathische en een verlaagde parasympathische activiteit, zowel bij patiënten met ED als in dierexperimenteel onderzoek. Deze disregulatie leidt tot een gestoorde neuronale NO-signaalwerking en tot endotheeldisfunctie [26].

Cardiale autonome disregulatie kan leiden tot een stijging van de hartslag door toename van de sympathische activiteit met tekenen van hartfalen. Ook dit is bekend bij patiënten met DM en patiënten met het MetS [27]. De erectiele functie en het cardiovasculaire systeem worden op gelijke wijze gereguleerd door het sympathische en parasympathische deel van het autonome zenuwstelsel. Vasculaire ED kan helpen bij het ontdekken van CVZ in een vroege fase [5], maar of ED ten gevolge van autonome disregulatie een toekomstige cardiovasculaire autonome neuropathie kan voorspellen, blijft nog onduidelijk.

De huidige kennis baseert zich voornamelijk op klinische studies en toekomstig onderzoek is nodig, zowel in dierexperimentele modellen als bij patiënten, om vast te kunnen stellen hoe de duur en de mate van autonome disregulatie invloed kunnen hebben op de reeds bekende mechanismen van neuronale activiteit en de weefselmorfologie en dan daaruit voortvloeiend, hoe deze disregulatie invloed kan hebben op de penisfunctie en het vasculaire systeem.

\section{Hormonen}

In deze sectie wordt onderzoek naar de link tussen testosteron en CVZ beschreven. Uit de meeste klinische studies blijkt dat een lagere testosteronspiegel gecorreleerd is met ED, CVZ, DM2 en metabole ziekten [28-30]. Ofschoon deze associatie sterk is en opvallend, is een oorzakelijk verband niet bewezen, aangezien het bewijs meestal voortkomt uit retrospectieve en observationele klinische studies. Daarom zijn we ook voor deze kennis en inzichten aangewezen op dierexperimentele studies over de link tussen testosteron en CVZ en de resultaten van de testosteron replacement therapy (TRT) bij hypogonadisme.

In geïsoleerde bloedvaten van dieren en de mens is testosteron in staat vasodilatatie te bewerken door stimulatie van de productie van NO via neuronal Nitric Oxide Synthase (nNOS) [31]. Ook heeft testosteron in dierexperimenteel onderzoek een beschermend effect tegen atherosclerose, met een afname van plaquevorming [32]. Omgekeerd ontwikkelen patiënten met androgeendeprivatietherapie wegens een gemetastaseerd prostaatcarcinoom reeds binnen drie maanden arteriële stijfheid en doet androgeendeprivatietherapie de vetmassa bij deze patiënten toenemen, evenals het LDL-cholesterol en de triglyceriden, en vermindert de insulinegevoeligheid [33]. 
Een laag testosterongehalte is gerelateerd aan een toename van oxidatieve stress bij mannen [34] en TRT bij mannen met symptomatisch hypogonadisme deed het niveau van circulerende ontstekingsfactoren (cytokinen) afnemen. Ook was langdurige TRT in staat om bij mannen met een laag testosterongehalte en symptomen van angina pectoris de dikte van de tunica intima en media van de coronaire arteriën te verminderen [35].

De beschikbare klinische data tonen aan, zij het niet geheel consistent, dat TRT bij hypogonadale mannen de viscerale adipositas en insulineresistentie kan verminderen en de lipide- en ontstekingsprofielen kan verbeteren [30, 36]. Het lage testosterongehalte en deze metabole stoornissen vormen hierbij een vicieuze cirkel, waarbij de beide factoren elkaar versterken, met name bij mannen met centrale adipositas door de hormonale activiteit van het viscerale vet als endocrien orgaan: toenemende aromatisatie van testosteron tot oestradiol in adipocyten leidt tot een stijging van het oestradiolgehalte, hetgeen vervolgens de testosteronproductie onderdrukt door inhibitie van de hypofysaire secretie van de gonadotrofinen. Aldus kan testosteron invloed hebben op de hoeveelheid lichaamsvet, de hoeveelheid steroïdhormonen, de hoeveelheid adipokinen, de insulinegevoeligheid en het glucosemetabolisme [37].

\section{Testosteron en ED}

Een te laag testosterongehalte kan invloed hebben op ieder van de essentiële fysiologische processen die tot een erectie leiden, zoals de neuronale activiteit ten behoeve van de arteriële bloedtoevoer naar de penis, de relaxatie van de gladde spiercellen van de corpora cavernosa en de veno-occlusie [38]. Ook kan testosteron de initiatie van de erectie beïnvloeden door de secretie van de hersenneurotransmitters te veranderen, zoals dopamine, oxytocine of NO van de mediale preoptische area [39]. Dierexperimenteel onderzoek laat zien dat circulerende androgenen neuroprotectief zijn en noodzakelijk voor zenuwregeneratie na een laesie [40].

Bij mannen met een laag testosterongehalte en bij gecastreerde knaagdieren worden veranderingen vastgesteld in de endotheliale morfologie, een afname van de gladde spiercellen in de trabekels van de corpora cavernosa en een verlies van elastische vezels in de tunica albuginea. Bij gecastreerde konijnen treedt een ophoping op van vetcellen onder de tunica albuginea, hetgeen de oorzaak van een gestoorde veno-occlusie kan zijn. Deze veranderingen van de structuur en functie van de corpora cavernosa zijn reversibel na TRT in een dierexperimenteel model [41].

Bij mannen die voorafgaand aan transgenderchirurgie androgeendeprivatietherapie ondergaan, en bij mannen met hypogonadisme treedt een significante afname op van de gladde spiercellen en een toename van collageen in de cor- pora cavernosa [42]. Maar de moleculaire mechanismen hierachter worden niet goed begrepen.

\section{Is er een relatie tussen testosteron, CVZ en ED?}

Hoewel de bewijzen voor een relatie tussen testosteron, CVZ en ED indrukwekkend zijn, blijven nog vele vragen open en dient de rol van testosteron in de ontwikkeling van ED en CVZ nader onderzocht te worden. Het gaat hierbij om vragen als: Hoe reguleert testosteron de atherogenese, de groeifactoren en de calciumflux? Wat doen testosteron, DHT en oestradiol precies en hoe verschilt de activiteit van de androgenen tussen dierlijk en humaan weefsel?

Ook de vraag wat eerder optreedt, de klachten van CVZ of die van ED, dient in meer detail beantwoord te worden.

De klinische voordelen van TRT dienen met grote zorgvuldigheid te worden beoordeeld:

- Een recente meta-analyse van RCT's die TRT en cardiovasculaire afwijkingen evalueerde, toonde een gunstiger resultaat in de door de industrie gesponsorde trials [43].

- In twee andere meta-analyses was geen enkele toename van cardiovasculaire risico's significant [44, 45].

- In een prospectieve evaluatie van oudere mannen in de Framingham Heart Study werd geen verband gezien tussen de concentratie van geslachtshormonen/ gonadotrofinen en klinisch optreden van CVZ en het risico van algehele mortaliteit gedurende een periode van tien jaar [46].

Samenvattend kan worden gesteld dat, hoewel de potentiële gezondheidsvoordelen van testosteron wellicht talrijk zijn, het onduidelijk blijft of één apart hormoon of factor van significante invloed kan zijn op het optreden van multifactoriële ziekten, zoals CVZ of all cause mortality.

Het onderzoek naar de link tussen ED en CVMZ bij de groep mannen met androgeendeprivatietherapie voor gemetastaseerd prostaatcarcinoom biedt een unieke kans om vast te stellen of testosteron de drijvende kracht hierachter is.

\section{Metabolomica}

Metabole ziekten hebben als gemeenschappelijk kenmerk de effecten op het glucose- en oxidatieve metabolisme. Bij hyperglykemie neemt de hoeveelheid eindproducten van de toegenomen glycatie toe, zowel in hart- als erectiel weefsel [47], hetgeen tot eiwitbeschadiging leidt met vernietigende effecten op de cellulaire functie, die weer verscheidene pathologische processen op gang brengen. Bij dislipidemie ligt dit anders: de samenhang tussen dislipidemie en cardiovasculaire complicaties bij MetS, DM2 en obesitas is bekend; studies naar deze samenhang bij ED ontbreken ten 
Hier staat een advertentie.

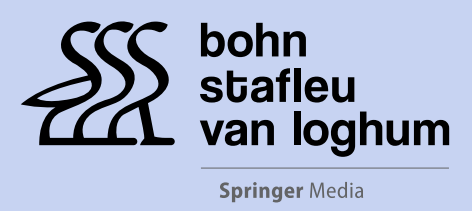

Houten 2017 
Hier staat een advertentie.

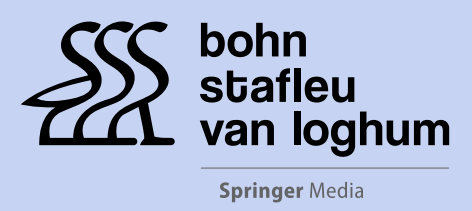

Houten 2017 
enenmale, waarbij wordt uitgegaan van de aanname dat bij deze ziekten alleen de hyperglykemie verantwoordelijk is voor ED. Derhalve is research naar een mechanistische verklaring voor ED door dislipidemie een belangrijk thema. In dat verband is het interessant dat ook een verhoogde hoeveelheid serumurinezuur een potentiële marker lijkt te zijn voor $\mathrm{ED}$, iets wat voor $\mathrm{HVZ}$ ook al in toenemende mate wordt erkend [48].

Mogelijk vormt de ontwikkeling van de zogeheten metabolome techniek een nieuwe weg in het vaststellen van gemeenschappelijke metabole veranderingen die plaatsvinden bij ED en HVZ. Deze techniek houdt in dat op de meest geavanceerde manier een kwantitatieve bepaling wordt verricht van chemische processen van de metabolieten. Metabolomische technologie heeft een gedetailleerd inzicht gegeven in het stofwisselingsprofiel van het cardiovasculaire weefsel en potentiële biomarkers angetoond voor myocardinfarct, cardiale shock, atherosclerose, atriumfibrilleren, cardiotoxiciteit door chemotherapie en hartfalen. Deze techniek is tot nu niet gebruikt voor het vaststellen van veranderingen in het erectiele weefsel en pelviene ganglia bij het ontstaan van ED.

\section{Samengevat}

Er zijn nog talloze vragen onbeantwoord bij het zoeken naar de gemeenschappelijke mechanistische relatie tussen ED en HVZ. Er is een overvloed aan literatuur die suggereert dat er een sterke relatie is tussen ED bij jonge mannen en aansluitend hartziekten, maar deze relatie is verre van opgehelderd. De International Society of Sexual Medicine en nu ook de American Urological Association (AUA) hebben het onderzoek en de behandeling van seksuele disfuncties tot hun topprioriteit verklaard, ter verbetering van de urologische gezondheid en om beter inzicht te verkrijgen in de link tussen ED en HVZ. Dat er een relatie is, wordt onderschreven.

Een uitgebreide lijst van toekomstige onderzoeksgebieden is gepubliceerd voor alle in dit artikel beschreven thema's.

Open Access This article is distributed under the terms of the Creative Commons Attribution 4.0 International License (http:// creativecommons.org/licenses/by/4.0/), which permits unrestricted use, distribution, and reproduction in any medium, provided you give appropriate credit to the original author(s) and the source, provide a link to the Creative Commons license, and indicate if changes were made.

\section{Literatuur}

1. Musicki B, Bella AJ, Bivalacqua TJ, Davies KP, DiSanto ME, Gonzalez-Cadavid NF, et al. Basic science evidence for the link be- tween erectile dysfunction and cardiometabolic dysfunction. J Sex Med. 2015;12(12):2233-55.

2. Impotence. NIH Consens Statement. Jan;10(4):1-33.

3. Lewis RW, Fugl-Meyer KS, Corona G, et al. Definitions/epidemiology/risk factors for sexual dysfunction. J Sex Med. 2010;7(4 Pt 2):1598-607.

4. Montorsi F, Briganti A, Salonia A, et al. Erectile dysfunction prevalence, time of onset and association with risk factors in 300 consecutive patients with acute chest pain and angiographically documented coronary artery disease. Eur Urol. 2003;44(3):360-4, discussion 364-5.

5. Lee JC, Bénard F, Carrier S, Talwar V, Defoy I. Do men with mild erectile dysfunction have the same risk factors as the general erectile dysfunction clinical trial population? BJU Int. 2011;107(6):956-60.

6. Thompson IM, Tangen CM, Goodman PJ, Probstfield JL, Moinpour $\mathrm{CM}$, Coltman CA. Erectile dysfunction and subsequent cardiovascular disease. JAMA. 2005;294(23):2996-3002.

7. Foroutan SK, Rajabi M. Erectile dysfunction in men with angiographically documented coronary artery disease. Urol J. 2007;4(1):28-32.

8. Banks E, Joshy G, Abhayaratna WP, et al. Erectile dysfunction severity as a risk marker for cardiovascular disease hospitalisation and all-cause mortality: a prospective cohort study. PLOS Med. 2013;10(1):e1001372.

9. Nehra A, Jackson G, Miner M, et al. The Princeton III Consensus recommendations for the management of erectile dysfunction and cardiovascular disease. Mayo Clin Proc. 2012;87(8):766-78.

10. Hatzimouratidis K, Salonia A, Adaikan G, et al. Pharmacotherapy for erectile dysfunction: recommendations from the fourth international consultation for sexual medicine(ICSM 2015). J Sex Med. 2016;13(4):465-88.

11. Jackson G, Boon N, Eardley I, Kirby M, Dean J, Hackett G, et al. Erectile dysfunction and coronary artery disease prediction: evidence-based guidance and consensus. Int $\mathrm{J}$ Clin Pract. 2010;64(7):848-57.

12. Villalba N, Martínez P, Bríones AM, et al. Differential structural and functional changes in penile and coronary arteries from obese Zucker rats. Am J Physiol Heart Circ Physiol. 2009;297(2):H696-H707.

13. Montorsi P, Ravagnani PM, Galli S, et al. The artery size hypothesis: a macrovascular link between erectile dysfunction and coronary artery disease. Am J Cardiol. 2005;96(12B):19M-23 M.

14. Ryu J-K, Jin H-R, Yin GN, et al. Erectile dysfunction precedes other systemic vascular diseases due to incompetent cavernous endothelial cell-cell junctions. J Urol. 2013;190(2):779-89, Aug.

15. Gratzke C, Angulo J, Chitaley K, et al. Anatomy, physiology, and pathophysiology of erectile dysfunction. J Sex Med. 2010;7(1 Pt 2):445-75.

16. Jin L, Teixeira CE, Webb RC, Leite R. Comparison of the involvement of protein kinase $\mathrm{C}$ in agonist-induced contractions in mouse aorta and corpus cavernosum. Eur J Pharmacol. 2008;590(13):363-8.

17. Vlachopoulos C, Rokkas K, Ioakeimidis N, Stefanadis C. Inflammation, metabolic syndrome, erectile dysfunction, and coronary artery disease: common links. Eur Urol. 2007;52(6):1590-600.

18. Kovanecz I, Rambhatla A, Ferrini MG, et al. Chronic daily tadalafil prevents the corporal fibrosis and veno-occlusive dysfunction that occurs after cavernosal nerve resection. BJU Int. 2008;101(2): 203-10.

19. Ponholzer A, Stopfer J, Bayer G, Susani M, Steinbacher F, Herbst $\mathrm{F}$, et al. Is penile atherosclerosis the link between erectile dysfunction and cardiovascular risk? An autopsy study. Int J Impot Res. 2012;24(4):137-40.

20. Caretta N, Palego P, Schipilliti M, Ferlin A, Di Mambro A, Foresta C. Cavernous artery intima-media thickness: a new parame- 
ter in the diagnosis of vascular erectile dysfunction. J Sex Med. 2009;6(4):1117-26.

21. Gandaglia G, Briganti A, Jackson G, Kloner RA, Montorsi F, Montorsi P, et al. A systematic review of the association between erectile dysfunction and cardiovascular disease. Eur Urol. 2014;65(5):968-78.

22. Andersson K-E. Mechanisms of penile erection and basis for pharmacological treatment of erectile dysfunction. Pharmacol Rev. 2011;63(4):811-59.

23. Saigal CS, Wessells H, Pace J, Schonlau M, Wilt TJ. Predictors and prevalence of erectile dysfunction in a racially diverse population. Arch Intern Med. 2006;166(2):207-12.

24. McCulloch DK, Campbell IW, Wu FC, Prescott RJ, Clarke BF. The prevalence of diabetic impotence. Diabetologia. 1980;18(4):279-83.

25. McDaid EA, Monaghan B, Parker AI, Hayes JR, Allen JA. Peripheral autonomic impairment in patients newly diagnosed with type II diabetes. Diabetes Care. 1994;17(12):1422-7.

26. Sánchez A, Contreras C, Martínez MP, Climent B, Benedito S, García-Sacristán A, et al. Role of neural NO synthase(nNOS) uncoupling in the dysfunctional nitrergic vasorelaxation of penile arteries from insulin-resistant obese Zucker rats. PLOS ONE. 2012;7(4):e36027.

27. Licht CMM, Geus EJC de, Penninx BWJH. Dysregulation of the autonomic nervous system predicts the development of the metabolic syndrome. J Clin Endocrinol Metab. 2013;98(6):2484-93.

28. Tirabassi G, Gioia A, Giovannini L, Boscaro M, Corona G, Carpi $\mathrm{A}$, et al. Testosterone and cardiovascular risk. Intern Emerg Med. 2013;8(S1):65-9.

29. Wang C, Jackson G, Jones TH, Matsumoto AM, Nehra A, Perelman MA, et al. Low testosterone associated with obesity and the metabolic syndrome contributes to sexual dysfunction and cardiovascular disease risk in men with type 2 diabetes. Diabetes Care. 2011;34(7):1669-75.

30. Kelly DM, Jones TH. Testosterone: a vascular hormone in health and disease. J Endocrinol. 2013; doi:10.1530/joe-12-0582.

31. Yildiz O, Seyrek M, Gul H, Un I, Yildirim V, Ozal E, et al. Testosterone relaxes human internal mammary artery in vitro. J Cardiovasc Pharmacol. 2005;45(6):580-5.

32. Campelo AE, Cutini PH, Massheimer VL. Testosterone modulates platelet aggregation and endothelial cell growth through nitric oxide pathway. J Endocrinol. 2012;213(1):77-87.

33. Levine GN, D'Amico AV, Berger P. Re: Androgen-Deprivation Therapy in Prostate Cancer and Cardiovascular Risk: A Science Advisory From the American Heart Association, American Cancer Society, and American Urological Association: endorsed by the American Society for Radiation Oncology. Eur Urol. 2010; doi:10. 1016/j.eururo.2010.07.013.

34. Mancini A, Leone E, Festa R, Grande G, Silvestrini A, Marinis L de, et al. Effects of testosterone on antioxidant systems in male secondary hypogonadism. J Androl. 2008;29(6):622-9.

35. Mathur A, Malkin C, Saeed B, Muthusamy R, Jones TH, Channer K. Long-term benefits of testosterone replacement therapy on angina threshold and atheroma in men. Eur $\mathrm{J}$ Endocrinol. 2009;161(3):443-9.

36. Kelly DM, Jones TH. Testosterone: a metabolic hormone in health and disease. J Endocrinol. 2013; doi:10.1530/JOE-12-0455.

37. Zitzmann M. Testosterone deficiency, insulin resistance and the metabolic syndrome. Nat Rev Endocrinol. 2009;5(12):673-81.

38. Köhler TS, Kim J, Feia K, Bodie J, Johnson N, Makhlouf A, et al. Prevalence of androgen deficiency in men with erectile dysfunction. Urology. 2008;71(4):693-7.

39. Suzuki N, Sato Y, Hisasue S-I, Kato R, Suzuki K, Tsukamoto T. Effect of testosterone on intracavernous pressure elicited with electrical stimulation of the medial preoptic area and cavernous nerve in male rats. J Androl. 2006;28(2):218-22.

40. Tehranipour M, Moghimi A. Neuroprotective effects of testosterone on regenerating spinal cord motoneurons in rats. J Mot Behav. 2010;42(3):151-5.

41. Traish A, Kim N. The physiological role of androgens in penile erection: regulation of corpus cavernosum structure and function. J Sex Med. 2005;2(6):759-70.

42. Tomada I, Tomada N, Almeida H, Neves D. Androgen depletion in humans leads to cavernous tissue reorganization and upregulation of Sirt1-eNOS axis. Age (Dordr). 2013;35(1):35-47.

43. Xu L, Freeman G, Cowling BJ, Schooling CM. Testosterone therapy and cardiovascular events among men: a systematic review and meta-analysis of placebo-controlled randomized trials. BMC Med. 2013;11:108.

44. Calof OM, Singh AB, Lee ML, Kenny AM, Urban RJ, Tenover $\mathrm{JL}$, et al. Adverse events associated with testosterone replacement in middle-aged and older men: a meta-analysis of randomized, placebo-controlled trials. J Gerontol A Biol Sci Med Sci. 2005;60(11):1451-7.

45. Haddad RM, Kennedy CC, Caples SM, Tracz MJ, Boloña ER, Sideras $\mathrm{K}$, et al. Testosterone and cardiovascular risk in men: a systematic review and meta-analysis of randomized placebo-controlled trials. Mayo Clin Proc. 2007;82(1):29-39.

46. Haring R, Teng Z, Xanthakis V, Coviello A, Sullivan L, Bhasin S, et al. Association of sex steroids, gonadotrophins, and their trajectories with clinical cardiovascular disease and all-cause mortality in elderly men from the Framingham Heart Study. Clin Endocrinol(oxf). 2013;78(4):629-34.

47. Neves D. Advanced glycation end-products: a common pathway in diabetes and age-related erectile dysfunction. Free Radic Res. 2013;47(Suppl 1):49-69.

48. Salem S, Mehrsai A, Heydari R, Pourmand G. Serum uric acid as a risk predictor for erectile dysfunction. J Sex Med. 2014;11(5): 1118-24.

49. Lue TF. Erectile dysfunction. N Engl J Med. 2000;342(24):1802 -13 .

dr. Herman H.J. Leliefeld uroloog 